\title{
Current Issues in the Diagnosis and Treatment of Endometrial Carcinoma
}

\author{
Aktuelle Aspekte zur Diagnostik und Therapie des Endometriumkarzinoms
}

Authors

Affiliation
J. Stubert, B. Gerber

Universitätsfrauenklinik und Poliklinik Rostock, Rostock

\section{Key words \\ - endometrial carcinoma \\ - paraaortic lymph node dissection \\ - endometrial thickness \\ - ultrasound \\ postmenopausal bleeding \\ Schlüsselwörter \\ - Endometriumkarzinom \\ - paraaortale Lymphknotendissektion \\ - Endometriumdicke \\ - Ultraschall \\ postmenopausale Blutung}

Deutsche Version unter: www.thieme-connect.de/ ejournals/gebfra

\section{received $\quad 2.8 .2015$ \\ revised 15.9.2015 \\ accepted 17.9.2015}

Bibliography

DOI http://dx.doi.org/

10.1055/s-0035-1558230

Geburtsh Frauenheilk 2016; 76:

170-175 ๑ Georg Thieme

Verlag KG Stuttgart . New York . ISSN 0016-5751

\section{Correspondence}

\section{Dr. med. Johannes Stubert}

Universitätsfrauenklinik

und Poliklinik Rostock

Südring 81

18059 Rostock

johannes.stubert@

uni-rostock.de

\section{Abstract \\ $\nabla$}

Endometrial carcinoma is the most common carcinoma of the female genital tract. Its most important clinical sign is postmenopausal bleeding. An endometrial biopsy is essential for diagnosis. Treatment decisions are governed by tumour risk assessment and patient comorbidity, which is often present. Pelvic and paraaortic lymph node dissection is unnecessary in low risk cases (definition: pT1 a, G1/2) and adjuvant radiotherapy and systemic treatments are usually avoidable. Treatment of high-risk patients (G3 and/or pT1b) and palliative cases is difficult and not well standardised. New molecular-based subtype classification may help treatment decision making in future.

\section{Introduction}

\section{$\nabla$}

According to the Robert Koch institute, the lifetime risk of endometrial carcinoma amongst German women is $2.2 \%$ (annual incidence approx. 28 new cases per 100000 women). It ranks fourth in gender specific carcinoma frequency and amongst gynaecological malignancies is second only to breast carcinoma [1]. With the main presenting symptom being postmenopausal bleeding (PMB), diagnosis is usually made early and prognosis thus comparatively favourable. $70 \%$ of cases are diagnosed at $\mathrm{T} 1$ stage and relative 5-year survival is around $81 \%$. Despite its relatively high incidence endometrial carcinoma is only in 11th place in cancer mortality statistics. With an average mean age at diagnosis of 69 years a significant proportion of patients die of comorbid, non-cancer related causes within 5 years of diagnosis (absolute 5 -year survival rate $72 \%$ ).

\section{Zusammenfassung \\ $\nabla$}

Das Endometriumkarzinom ist das häufigste Karzinom des weiblichen Genitales. Führendes klinisches Zeichen ist die postmenopausale Blutung. Für die Diagnosestellung ist immer eine Endometriumbiopsie notwendig. Die Therapieentscheidung hängt von der Risikoeinschätzung des Karzinoms und der häufig vorliegenden Komorbidität ab. In Fällen mit niedrigem Risiko (Definition: pT1 a, G1/2) ist eine pelvine und paraaortale Lymphknotendissketion unnötig. Eine adjuvante Bestrahlung und eine Systemtherapie sind zumeist vermeidbar. Die Behandlung von Hochrisikopatientinnen (G3 und/oder pT1b) und von Patientinnen in palliativer Situation ist schwierig und weniger gut standardisiert. Neue, molekular definierte Subtypen könnten hier zukünftig Therapieentscheidungen erleichtern.

Current topics of discussion include the diagnostic process and the development of stage-appropriate treatment protocols that avoid over treatment while ensuring optimal management of patients with high recurrence risk.

\section{Synopsis}

$\nabla$

Is biopsy essential for postmenopausal bleeding (PMB) when the endometrium is thin?

PMB is usually the main clinical sign of endometrial carcinoma. It is mostly an early symptom of the disease and should prompt the clinician to perform an endometrial biopsy. In Germany and most western European countries this is performed via hysteroscopy and fractionated curettage. The validity of fractionation is however questionable since differentiation between cervix and corpus is imprecise and therapeutic conse- 
Table 1 Risk factors for the development of endometrial carcinoma.

\begin{tabular}{|l|l|}
\hline Risk factor & $\begin{array}{l}\text { Estimated } \\
\text { relative risk }\end{array}$ \\
\hline Obesity & $\mathbf{2 - 5}$ \\
\hline Increased age & $2-3$ \\
\hline PCO Syndrome (anovulation) & $>5$ \\
\hline Early menarche & $1.5-2$ \\
\hline Late menopause & $2-3$ \\
\hline Nulliparity/infertility & 3 \\
\hline Tamoxifen & $2-3(7)$ \\
\hline Long-term oestrogen substitution without progesterone & $6-9$ \\
\hline Oral contraceptives & 0.5 \\
\hline Diabetes mellitus type 2 & $2-3$ \\
\hline
\end{tabular}

quences rarely follow. Vacuum aspiration biopsy is an alternative method of tissue sampling that is seldom practiced in Germany and elsewhere [2]. It requires no anaesthesia and can be performed on an outpatient basis. The optional use of local anaesthesia e.g. $20 \%$ benzocaine spray simplifies sampling by allowing fixation of the uterus by grasping the anterior lip of the cervix with a tenaculum. Dilatation of the cervix is usually not necessary prior to insertion of the $3.1 \mathrm{~mm}$ thick polypropylene biopsy catheter. Given that it is now possible to assess the endometrium with high-resolution transvaginal ultrasound, the question arises whether endometrial biopsy can be avoided in certain patients with PMB. In one metaanalysis endometrial carcinoma was present in $8.9 \%$ of approximately 2900 patients with PMB [3]. With a threshold of $3 \mathrm{~mm}$ for endometrial thickness $97.9 \%$ of carcinomas would have been diagnosed with a false positive rate of $64.6 \%$ (i.e. almost $2 / 3$ of patients without carcinoma also had endometrial thickness $>3 \mathrm{~mm}$ ). When endometrial thickness was $\leq 3 \mathrm{~mm}$ the likelihood of carcinoma dropped from 10 to $0.6 \%$ despite the presence of PMB. The authors concluded that endometrial biopsy could be avoided when endometrial thickness was $\leq 3 \mathrm{~mm}$. Undiagnosed cases of type 2 serous endometrial carcinoma remain a problem with this approach. The working group for gynaecological oncology (AGO) of the German Society of Obstetrics and Gynaecology therefore recommends histological assessment of all cases of PMB using hysteroscopy and fractionated curettage [4]. Defining indications for the investigation of perimenopausal bleeding remains difficult. There should be a low threshold for curettage for menorrhagia and metrorrhagia, especially after an extended bleeding-free interval or when typical risk factors such as the metabolic syndrome are present.

\section{Is biopsy indicated for endometrial thickening} in postmenopausal women without bleeding?

A British case-control study that included over 48000 postmenopausal women without PMB correlated the incidence of endometrial carcinoma or atypical hyperplasia within a year of study inclusion with endometrial thickness [5]. Endometrial thickness was $\geq 5 \mathrm{~mm}$ in $77.1 \%$ of women with carcinoma, however, had this measure been used as the indication for histological investigation, carcinoma would have been present in only $1.4 \%$ of cases investigated. By far the majority would have had no carcinoma. Put another way, in the absence of PMB 58 women would need to be investigated histologically to diagnose one case of carcinoma [6]. And despite this rather low threshold for investigation $19 \%$ of carcinomas would still be missed. Histology should thus not be performed solely on the basis of ultrasound criteria. It is also doubtful whether early carcinoma detection improves prognosis; there are no prospective data on the subject. A retrospective analysis showed no prognostic advantage with early ultrasonographic carcinoma detection [7]. There was no difference in disease-free survival or overall survival between patients whose carcinomas were diagnosed solely on ultrasound criteria (endometrium $\geq 10 \mathrm{~mm}$ and/or endometrial irregularity) and those diagnosed because of PMB, provided that bleeding was investigated within 8 weeks of its occurrence [7]. Other retrospective analyses have also shown no difference in disease-free or overall survival between asymptomatic patients and those with PMB [8, 9]. Ultimately a significant number of endometrial carcinomas may never become clinically apparent, as was shown in an autopsy study that found a 4-6 times higher incidence $[6,10]$. In summary, current data do not support ultrasound screening for endometrial carcinoma and further investigation of incidental endometrial thickening in the absence of PMB provides no benefit. This also applies to patients at increased risk, such as those with the metabolic syndrome and current tamoxifen therapy [11]. The only exception is proven Lynch syndrome, where the life-time risk of endometrial carcinoma is $40-60 \%$ [12]. Approximately $1.8 \%$ of endometrial carcinomas are presumed due to Lynch syndrome (incidence approx. 1:500), these tumours occurring more frequently before the menopause. Thus tissue samples from patients under 50 years of age should be specifically tested for the presence of this syndrome [13], which is an autosomal dominantly inherited disorder of mismatch repair genes that can be diagnosed on history using the Amsterdam criteria [12]. Where the disease is present vaginal ultrasound and endometrial vacuum aspiration biopsy are advised annually from the age of 35 years. In addition prophylactic hysterectomy should be considered once family planning is complete.

\section{Treatment of precursor lesions}

In contrast to the 1994 WHO classification, which subdivided endometrial hyperplasia into four categories, the current simplified classification from 2014 only discriminates between forms of hyperplasia with and without atypia [14]. Atypical hyperplasia (syn. endometrial intraepithelial neoplasia [EIN]) shows many of the molecular genetic changes of invasive carcinoma, yet only the presence of atypia is associated with a definite increase in carcinoma risk ( Table 3) [15]. The expected rate of carcinoma development within 10 years is about $30 \%$ [16]. When considering the risk of progression to invasive carcinoma it should be taken into account that invasive carcinomas are found in up to $48 \%$ of hysterectomy samples in this setting $[17,18]$. In addition, one study found that atypical hyperplasia was reclassified as invasive carcinoma on second pathological assessment in $29 \%$ of cases [17]. In contrast, the development of invasive carcinoma was very seldom in cases of hyperplasia without atypia $(<5 \%)$ [16].

The following treatment recommendations can be deduced: Hyperplasia without atypia can be treated conservatively. Progesterone therapy is recommended in premenopausal patients (e.g. 10-20 mg MPA on cycle days 12-25). Alternatively local treatment in the form of a progesterone containing intrauterine pessary (e.g. Mirena ${ }^{\circledR}$ ) is recommended or a monophasic progesterone dominant contraceptive in PCO syndrome with an irregular cycle. Hormonal IUDs produce better endometrial regression rates than oral treatments (95-100\% vs. $64-84 \%$ respectively) $[19,20]$. Ultrasound should be repeated after 3 to 6 months and if abnormal a repeat curettage performed [21]. Continuous progesterone therapy ( $2.5 \mathrm{mg}$ MPA daily) should be considered in 
Table 2 Lesions and their likelihood of progression [15]. The current WHO hyperplasia classification only considers the presence or absence of atypia.

\begin{tabular}{|l|l|}
\hline Type & $\begin{array}{l}\text { Progression to invasive } \\
\text { carcinoma (on average } \\
\text { after 13.4 years) }\end{array}$ \\
\hline Simple hyperplasia & $1 \%$ \\
\hline Complex hyperplasia & $3 \%$ \\
\hline Simple hyperplasia with atypia & $8 \%$ \\
\hline Complex hyperplasia with atypia & $29 \%$ \\
\hline
\end{tabular}

postmenopausal patients, a possible alternative being regular follow-up without medical treatment. Hysterectomy is recommended if atypia is found. An individualised approach is necessary for patients who still wish to fall pregnant. Women must be informed that despite progesterone therapy atypia will persist in $14 \%$ of cases and $3-7 \%$ will progress $[22,23]$. Ultimately a quarter of cases will recur, the most important risk factor being obesity (body mass index $\geq 35 \mathrm{~kg} / \mathrm{m}^{2}$ ) in which case treatment with metformin is recommended [24]. Here again the levonorgestrel containing free intrauterine pessary (Mirena ${ }^{\circledR}$ ) produces better results than oral progesterone $[25,26]$. Close ultrasound monitoring of the endometrium and repeat biopsy after 3 and 6 months are essential, as is hysterectomy as soon as family planning is complete. MRI provides a additional option for estimating infiltration depth ( Fig. 1).

\section{New molecular classification}

Tumour stage ( Table 2 ) and grade of differentiation remain important prognostic factors for endometrial carcinoma. In addition, the histological subtype carries prognostic significance. As per the classical view, endometrioid type 1 carcinoma and serous/clear cell type 2 carcinoma [27] are differentiated. The first of these (type 1 carcinoma) develops on a background of chronic oestrogen stimulation (classical risk factor!) ( Table 1) with progression through the precursor stages of hyperplasia; prognosis is generally favourable. The second (type 2 carcinoma) occurs in $30 \%$ of cases. These tumours develop independently of oestrogen on background atrophic endometrium. They are characterised by poor differentiation, are highly aggressive and at diagnosis tumour stage is often advanced (FIGO III-IV). Both subtypes are associated with characteristic mutation patterns (type 1:

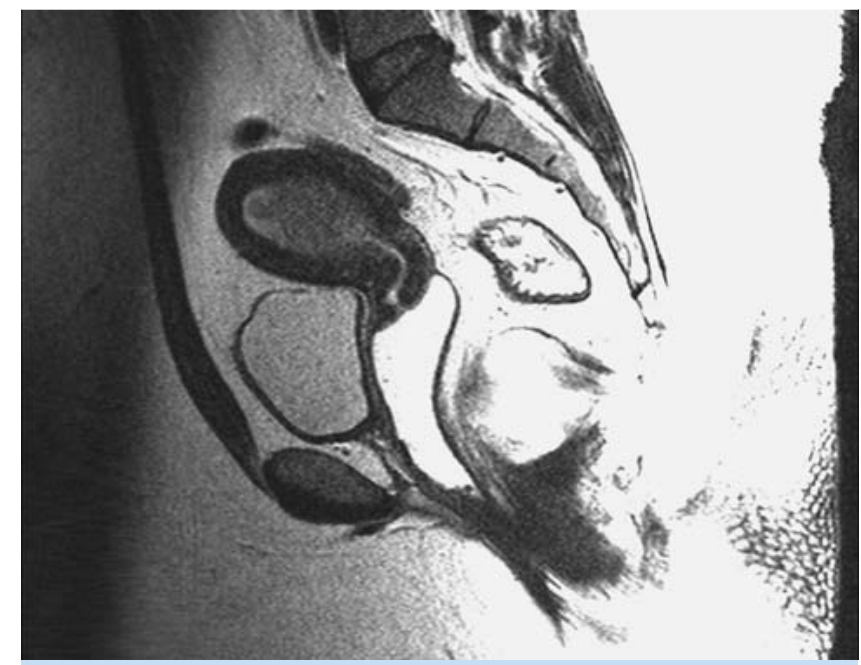

Fig. 1 High resolution pelvic MRI with gel-filled vagina. 25-year-old patient (BMI $59.5 \mathrm{~kg} / \mathrm{m}^{2}$ ) with histologically confirmed endometrioid adenocarcinoma of the uterine corpus; previous fractionated curettage for hypermenorrhea. Intrauterine tumour with surrounding myometrium prior to surgery. Postoperative classification: pT1b (infiltration depth max. 17/20 mm) pN1 (1/36) cM0 L1 Pn0 V0 R0 G2. Microsatellite instability not present (consistently positive expression of MLH1, MSH2, MSH6 and PMS2).

PTEN mutation in up to $80 \%$, type 2: p53 mutation in over $90 \%$ ). More recent molecular genetic analyses have shown that endometrioid type 1 carcinomas in particular should be further divided into subclasses. Some endometrioid carcinomas should even be grouped together with serous type 2 carcinoma. Currently 4 subclasses with differing prognoses are differentiated; these may be essential for future risk-adapted treatment decision making ( Table 3) [27,28]. Of particular importance in this regard is the fact that hypermutated carcinomas express numerous neoantigens, thus presenting potential targets for the mediation of an inherent immune response. This antitumour cytotoxicity is however prevented by the self tolerance mediated interaction of lymphocytic PD (programmed death) receptors and their ligands (PD-L1) on tumour cells [29]. The antibody mediated blockade of this "rescue" mechanism by so-called immune checkpoint inhibitors may be meaningful for future treatment, and is currently the focus of clinical studies [30].

Table 3 Molecular classification of endometrial carcinoma [27,28]. Four subtypes are defined. The POLE (polymerase $\varepsilon$ ) mutated forms (5-6\% of all endometrial carcinomas, mostly in younger women) have a good prognosis despite high mutation rates. MSI type is associated with Lynch syndrome. A subgroup of endometrioid carcinoma is molecular biologically grouped together with serous carcinomas.

\begin{tabular}{|c|c|c|c|c|}
\hline Type & $\begin{array}{l}\text { POLE } \\
\text { (ultramutated) }\end{array}$ & $\begin{array}{l}\text { MSI } \\
\text { (hypermutated) }\end{array}$ & $\begin{array}{l}\text { Copy number low } \\
\text { (endometrioid) }\end{array}$ & $\begin{array}{l}\text { Copy number high } \\
\text { (serous-like) }\end{array}$ \\
\hline Copy number aberrations & low & low & low & high \\
\hline MSI/MLH1 methylation* & $\begin{array}{l}\text { mixed high and low MSI, } \\
\text { stable }\end{array}$ & high MSI & MSI stable & MSI stable \\
\hline Mutation rate & very high & high & low & low \\
\hline $\begin{array}{l}\text { Selection of commonly mutated genes } \\
\text { (frequency in \%) }\end{array}$ & $\begin{array}{l}\text { POLE }(100 \%) \\
\text { PTEN }(94 \%)\end{array}$ & PTEN (88\%) & PTEN (77\%) & TP53 (92\%) \\
\hline Histological subtype & endometrioid & endometrioid & endometrioid & $\begin{array}{l}\text { serous, endometrioid } \\
\text { and mixed }\end{array}$ \\
\hline Grade & G1-3 & G1-3 & G1-2 & G3 \\
\hline Prognosis & good & moderate & moderate & poor \\
\hline
\end{tabular}

* MSI - microsatellite instability, MLH1 - mismatch repair gene inactivated by DNA methylation; if there is a germline mutation Lynch syndrome is present. 


\section{When is lymph node dissection indicated?}

Lymph node metastases occur in less than two percent of low risk endometrial carcinomas (pT1 a G1/2) [31]. In this context lymph node dissection carries no therapeutic benefit and it significantly increases morbidity, thus increasing treatment costs [32-35]. The disease-specific 5-year survival rate at this stage is over $95 \%$ even without lymph node dissection, which should thus not be performed [36]. The risk of lymphatic spread increases dramatically with myometrial infiltration of over $50 \%$ and in poorly differentiated carcinoma (G3)/the serous/clear cell subtype. Here lymph node dissection should be aimed for. In view of lymphatic drainage via the parametrium (caudal part) as well as via the adnexia (cranial part) both pelvic and paraaortic lymph nodes should be systematically removed. Ideally a pathologist should be available for intraoperative frozen section analysis.

\section{What type of hysterectomy?}

According to results of the GOG Lap2 trial the laparoscopic and conventional (laparotomy) hysterectomy approaches are equivalent from the oncological perspective [37]. After 5 years there was no significant difference in recurrence rate (11.4 vs. $10.2 \%$, HR 1.14) or overall survival. Approximately $70 \%$ of patients included in the trial had FIGO stage IA carcinomas. On average patients who underwent a laparoscopic hysterectomy were mobilised more quickly and had fewer complications. Obese patients in particular benefitted from the laparoscopic approach despite increased technical difficulty in this context.

Comorbid illnesses, particularly more severe adiposity, are often limiting factors in the operative treatment of endometrial carcinoma. In these cases vaginal hysterectomy (with removal of the adnexa where possible) is an alternative with few complications and a 5 -year survival rate of over $90 \%$ for FIGO stage I tumours [38].

Previously, assuming parametrial tumour spread, radical hysterectomy was recommended for carcinoma involvement of the cervix. However pathological studies have shown that infiltration of the parametrium occurs in less than ten percent of carcinomas even amongst those that are locally advanced. In an analysis of 334 radical hysterectomy specimens none of the 16 FIGO stage II tumours showed parametrial infiltration and less than $20 \%$ of all cases of parametrial infiltration had cervical involvement [39]. Parametrial spread was most often found (21.3\%) in FIGO stage III tumours (old classification). The prognosis at this stage is however determined by the high rate of distant metastases. The AGO no longer recommends parametrial resection for FIGO stage II carcinoma.

\section{The role of adjuvant radiotherapy \\ for FIGO stage I carcinoma}

The indication for adjuvant radiotherapy at FIGO stage I is riskbased. According to a Cochrane metaanalysis (7 trials, 3628 patients) percutaneous radiotherapy (teletherapy) reduces locoregional recurrence (HR 0.36; 95\% Cl 0.25-0.52) without improving overall or carcinoma specific survival - this also applies to highrisk FIGO stage I cases [40]. This may partly be due to the fact that radiation does not influence the occurrence of distant metastases (RR 1.04, 95\% CI 0.80-1.35). In low-risk cases (G1/2, pT1 a) teletherapy even appears to be disadvantageous; carcinoma specific survival was worse for this important subgroup (RR 2.64; 95\% CI 1.05-6.66). A 20-year follow-up of a Norwegian trial ( $\mathrm{n}=568 \mathrm{pa}-$ tients) showed that teletherapy provided no survival advantage for stage I carcinoma. In fact mortality among patients under the age of 60 was significantly higher in the group receiving percutaneous radiation (HR 1.36; $95 \%$ CI 1.06-1.76); this was probably due to a higher rate of secondary carcinomas (HR 2.02; $95 \% \mathrm{CI}$ 1.30-3.15) [41]. In addition there was increased teletherapy-associated morbidity in the form of chronic radiation damage to bladder and bowel. On direct comparison [42] brachytherapy was no less effective than teletherapy for FIGO stage I tumours in terms of locoregional recurrence rate. The risk-reducing effects of brachytherapy for low-risk cases is so slight [43] that radiation should be avoided in this situation (G1/2, pT1 a, endometrioid type). Brachytherapy is currently recommended for intermediate risk cases (FIGO stage IA and G3 or FIGO stage IB and G1/2); the PORTEC-4 trial is currently assessing whether radiation can be avoided in this setting. High-risk cases ( $\geq$ FIGO stage IB, G3) should receive adjuvant radiotherapy - the decision to use percutaneous forms should be made on an individual basis (e.g. when lymph node staging is not performed).

\section{When should systemic adjuvant therapy} be recommended?

The prognosis of endometrioid carcinomas above FIGO stage IB, G3 and all serous-papillary/clear cell subtypes is unfavourable with 5 -year survival rates under $60 \%$ [44]. The poor prognosis is due to a high rate of distant metastases and is only improved by effective systemic adjuvant therapy. All randomised, controlled trials with high-risk cases were included in a Cochrane metaanalysis [45]. Almost all trials were platinum-based (cisplatin). The efficacy of adjuvant chemotherapy was compared to a) no further systemic treatment after standard surgery and radiotherapy or $\mathrm{b}$ ) compared directly to adjuvant radiotherapy. It was shown that adjuvant chemotherapy significantly improved overall 5-year survival (HR 0.88; 95\% CI 0.79-0.99). There was a 3\% absolute reduction in risk of death. 30 patients had to be treated to prevent one death (number needed to treat, NNT). The effect was even greater (NNT 25) when only the more recent platinum-based trials were considered. The positive effect was most obvious on direct comparison of chemotherapy vs. radiotherapy (HR 0.87; 95\% CI 0.76-0.99); only a positive trend was shown for adjuvant chemotherapy on a background of previous adjuvant radiation (HR 0.94; 95\% CI 0.72-1.22). The AGO advises sequential adjuvant carboplatin-paclitaxel chemotherapy and radiotherapy from FIGO stage IB, G3 up to FIGO stage III and for all serous and clear cell carcinomas. Adjuvant endocrine therapy has shown no efficacy and the AGO specifically advises against it.

The high rate of often severe comorbidity in these patients needs to be taken into account in practice. It is often the decisive lifelimiting factor, relativising the purported therapeutic benefits of adjuvant systemic therapy. At the very least, comorbidity severely limits chemotherapy options.

\section{Treatment options for tumour recurrence}

There is little data to support treatment recommendations for tumour recurrence. Operative removal of locoregional and intraabdominal recurrences should be attempted wherever possible with complete tumour excision being the primary aim. Radiotherapy is indicated for inoperable tumours and postoperative residual tumour. Intraoperative clip marking can help to better define radiation volume. Palliative systemic therapy should be reserved for cases in which the above mentioned options are not possible. Analogous to adjuvant therapy recommended first line treatment is platinum-based chemotherapy, if necessary in combination with a taxane. Anthracyclines are an alternative 
Table 4 Response rates for endocrine therapy in palliative cases of endocrine sensitive (hormone receptor positive) low-grade carcinomas [47]. Response to commonly used monochemotherapeutic agents is comparable (10-20\%).

\begin{tabular}{|l|l|}
\hline Endocrine substance & Response rate \\
\hline Progesterones (e.g. MPA $200 \mathrm{mg} / \mathrm{d}$ ) & $11-56 \%$ \\
\hline Tamoxifen & $10-35 \%$ \\
\hline GnRH analogues & $11 \%$ \\
\hline Aromatase inhibitors & $9 \%$ \\
\hline Fulvestrant & proven efficacy \\
\hline Onapristone (progesterone receptor antagonist) & $?$ \\
\hline
\end{tabular}

although pegylated liposomal doxorubicin is preferable in view of better tolerance [46]. Other drugs such as ifosfamide, topotecan and ixabepilone used as monotherapy have response rates of $10-20 \%$. Endocrine therapy can be considered in low-grade tumours that are oestrogen and/or progesterone receptor positive. Response rates for the individual substances are comparable (० Table 4) [47].

\section{Uterine carcinosarcoma: a special case}

With the most unfavourable prognosis of all, uterine carcinosarcoma (syn. malignant mixed Mullerian tumour) should be managed surgically as for high-risk endometrial carcinoma: hysterectomy and removal of the adnexa plus pelvic and paraaortic lymph node dissection [48]. Here too radiotherapy reduces the risk of local recurrence but does not improve survival [49]. Adjuvant chemotherapy may improve survival when the tumour is locally advanced and after surgical management of tumour recurrence. A combination of ifosfamide and paclitaxel (GOG 161 study) is recommended or alternatively paclitaxel combined with carboplatin (less toxicity, response rates of $54-62 \%$ ).

\section{Conclusion}

In most cases endometrial carcinoma is diagnosed early due to postmenopausal bleeding. Ultrasound measurement of endometrial thickness can be helpful in the risk assessment of tumour occurrence, however since its use has not been shown to improve prognosis, and since type 2 carcinomas that occur on a background atrophic endometrium may be missed, ultrasound alone should not be relied on for early tumour detection in asymptomatic women, nor should it be the sole instrument of diagnostic decision making in the assessment of postmenopausal bleeding. Both lymph node dissection and radiotherapy can be avoided in the management of early stage disease with low recurrence risk. In contrast high-risk carcinoma requires multimodal treatment consisting of extensive surgery plus radiotherapy and chemotherapy. Comorbidity in this patient population, however, makes management strictly according to guidelines impossible in many cases. New molecular biologically based risk classification is likely to be relevant to treatment decision making in future.

\section{Conflict of interest}

$\nabla$

The authors declare no conflict of interest.

\section{References}

1 Robert Koch-Institut; Gesellschaft der epidemiologischen Krebsregister in Deutschland e.V., Hrsg. Krebs in Deutschland 2009/2010. 9. Ausgabe. Berlin: 2013

2 Zuber TJ. Endometrial biopsy. Am Fam Physician 2001; 63: 1131-1135; $1137-1141$

3 Timmermans A, Opmeer BC, Khan KS et al. Endometrial thickness measurement for detecting endometrial cancer in women with postmenopausal bleeding: a systematic review and meta-analysis. Obstet Gynecol 2010; 116: 160-167

4 AGO-Kommission Uterus. Empfehlungen für die Diagnostik und Therapie des Endometriumkarzinoms. April 2015. Online: http://www.agoonline.de/fileadmin/downloads/leitlinien/uterus/empfehlungen_ diagnostik_therapie_EC.pdf; last access: 02.08.2015

5 Jacobs I, Gentry-Maharaj A, Burnell M et al. Sensitivity of transvaginal ultrasound screening for endometrial cancer in postmenopausal women: a case-control study within the UKCTOCS cohort. Lancet Oncol $2011 ; 12: 38-48$

6 Vergote I, Amant F, Timmerman D. Should we screen for endometrial cancer? Lancet Oncol 2011; 12: 4-5

7 Gerber B, Krause A, Muller $H$ et al. Ultrasonographic detection of asymptomatic endometrial cancer in postmenopausal patients offers no prognostic advantage over symptomatic disease discovered by uterine bleeding. Eur J Cancer 2001; 37: 64-71

8 Barak F, Kalichman L, Gdalevich $M$ et al. The influence of early diagnosis of endometrioid endometrial cancer on disease stage and survival. Arch Gynecol Obstet 2013; 288: 1361-1364

9 Seebacher V, Schmid M, Polterauer S et al. The presence of postmenopausal bleeding as prognostic parameter in patients with endometrial cancer: a retrospective multi-center study. BMC Cancer 2009; 9: 460

10 Horwitz RI, Feinstein AR, Horwitz SM et al. Necropsy diagnosis of endometrial cancer and detection-bias in case/control studies. Lancet 1981; 2: 66-68

11 Gerber B, Krause A, Muller H et al. Effects of adjuvant tamoxifen on the endometrium in postmenopausal women with breast cancer: a prospective long-term study using transvaginal ultrasound. J Clin Oncol 2000; 18: 3464-3470

12 Steinke V, Engel C, Buttner R et al. Hereditary nonpolyposis colorectal cancer (HNPCC)/Lynch syndrome. Dtsch Arztebl Int 2013; 110: 32-38

13 Uterine Neoplasms - NCCN Clinical Practice Guidelines in Oncology. Version 2.2015. 2015. Online: https://www.nccn.org/store/login/ login.aspx?ReturnURL=http://www.nccn.org/professionals/physician_ gls/pdf/uterine.pdf; last access: 02.08.2015

14 Emons G, Beckmann MW, Schmidt D et al. New WHO classification of endometrial hyperplasias. Geburtsh Frauenheilk 2015; 75: 135-136

15 Kurman RJ, Kaminski PF, Norris HJ. The behavior of endometrial hyperplasia. A long-term study of "untreated" hyperplasia in 170 patients. Cancer 1985; 56: 403-412

16 Lacey JV jr., Sherman ME, Rush BB et al. Absolute risk of endometrial carcinoma during 20-year follow-up among women with endometrial hyperplasia. J Clin Oncol 2010; 28: 788-792

17 Trimble CL, Kauderer J, Zaino R et al. Concurrent endometrial carcinoma in women with a biopsy diagnosis of atypical endometrial hyperplasia: a Gynecologic Oncology Group study. Cancer 2006; 106: 812-819

18 Suh-Burgmann E, Hung YY, Armstrong MA. Complex atypical endometrial hyperplasia: the risk of unrecognized adenocarcinoma and value of preoperative dilation and curettage. Obstet Gynecol 2009; 114: 523-529

19 Gallos ID, Krishan P, Shehmar M et al. LNG-IUS versus oral progestogen treatment for endometrial hyperplasia: a long-term comparative cohort study. Hum Reprod 2013; 28: 2966-2971

20 Dolapcioglu K, Boz A, Baloglu A. The efficacy of intrauterine versus oral progestin for the treatment of endometrial hyperplasia. A prospective randomized comparative study. Clin Exp Obstet Gynecol 2013; 40: $122-126$

21 Denschlag $D$, Ulrich $U$, Emons $G$. The diagnosis and treatment of endometrial cancer: progress and controversies. Dtsch Arztebl Int 2010; 108: 571-577

22 Gunderson CC, Fader AN, Carson KA et al. Oncologic and reproductive outcomes with progestin therapy in women with endometrial hyperplasia and grade 1 adenocarcinoma: a systematic review. Gynecol Oncol 2012; 125: 477-482 
23 Gallos ID, Yap J, Rajkhowa $M$ et al. Regression, relapse, and live birth rates with fertility-sparing therapy for endometrial cancer and atypical complex endometrial hyperplasia: a systematic review and metaanalysis. Am J Obstet Gynecol 2012; 207: 266.e1-266.e12

24 Shan $W$, Wang $C$, Zhang $Z$ et al. Conservative therapy with metformin plus megestrol acetate for endometrial atypical hyperplasia. J Gynecol Oncol 2014; 25: 214-220

25 Orbo A, Vereide A, Arnes $M$ et al. Levonorgestrel-impregnated intrauterine device as treatment for endometrial hyperplasia: a national multicentre randomised trial. BJOG 2014; 121: 477-486

26 Gallos ID, Shehmar M, Thangaratinam S et al. Oral progestogens vs. levonorgestrel-releasing intrauterine system for endometrial hyperplasia: a systematic review and metaanalysis. Am J Obstet Gynecol 2010; 203: 547.e1-547.e10

27 Murali R, Soslow RA, Weigelt B. Classification of endometrial carcinoma: more than two types. Lancet Oncol 2014; 15: e268-e278

28 Cancer Genome Atlas Research Network, Kandoth C, Schultz N et al. Integrated genomic characterization of endometrial carcinoma. Nature 2013; 497: 67-73

29 McDermott DF, Atkins MB. PD-1 as a potential target in cancer therapy. Cancer Med 2013; 2: 662-673

30 Le DT, Uram JN, Wang H et al. PD-1 blockade in tumors with mismatchrepair deficiency. N Engl J Med 2015; 372: 2509-2520

31 Milam MR, Java J, Walker JL et al. Nodal metastasis risk in endometrioid endometrial cancer. Obstet Gynecol 2012; 119: 286-292

32 Benedetti Panici P, Basile S, Maneschi F et al. Systematic pelvic lymphadenectomy vs. no lymphadenectomy in early-stage endometrial carcinoma: randomized clinical trial. J Natl Cancer Inst 2008; 100: 17071716

33 ASTEC study group, Kitchener H, Swart AM et al. Efficacy of systematic pelvic lymphadenectomy in endometrial cancer (MRC ASTEC trial): a randomised study. Lancet 2009; 373: 125-136

34 Todo Y, Kato H, Kaneuchi $M$ et al. Survival effect of para-aortic lymphadenectomy in endometrial cancer (SEPAL study): a retrospective cohort analysis. Lancet 2010; 375: 1165-1172

35 Dowdy SC, Borah BJ, Bakkum-Gamez JN et al. Prospective assessment of survival, morbidity, and cost associated with lymphadenectomy in low-risk endometrial cancer. Gynecol Oncol 2012; 127: 5-10

36 Bell JG, Patterson DM, Klima J et al. Outcomes of patients with low-risk endometrial cancer surgically staged without lymphadenectomy based on intra-operative evaluation. Gynecol Oncol 2014; 134: 505509
37 Walker JL, Piedmonte MR, Spirtos NM et al. Recurrence and survival after random assignment to laparoscopy versus laparotomy for comprehensive surgical staging of uterine cancer: Gynecologic Oncology Group LAP2 Study. J Clin Oncol 2012; 30: 695-700

38 Lelle RJ, Morley GW, Peters WA. The role of vaginal hysterectomy in the treatment of endometrial carcinoma. Int J Gynecol Cancer 1994; 4: 342-347

39 Watanabe Y, Satou T, Nakai H et al. Evaluation of parametrial spread in endometrial carcinoma. Obstet Gynecol 2010; 116: 1027-1034

40 Kong A, Johnson N, Kitchener HC et al. Adjuvant radiotherapy for stage I endometrial cancer: an updated Cochrane systematic review and meta-analysis. J Natl Cancer Inst 2012; 104: 1625-1634

41 Onsrud M, Cvancarova M, Hellebust TP et al. Long-term outcomes after pelvic radiation for early-stage endometrial cancer. J Clin Oncol 2013; 31: 3951-3956

42 Nout RA, Smit VT, Putter $H$ et al. Vaginal brachytherapy versus pelvic external beam radiotherapy for patients with endometrial cancer of high-intermediate risk (PORTEC-2): an open-label, non-inferiority, randomised trial. Lancet 2010; 375: 816-823

43 Sorbe B, Nordstrom B, Maenpaa J et al. Intravaginal brachytherapy in FIGO stage I low-risk endometrial cancer: a controlled randomized study. Int J Gynecol Cancer 2009; 19: 873-878

44 Pectasides D, Pectasides E, Economopoulos T. Systemic therapy in metastatic or recurrent endometrial cancer. Cancer Treat Rev 2007; 33: 177-190

45 Johnson N, Bryant A, Miles T et al. Adjuvant chemotherapy for endometrial cancer after hysterectomy. Cochrane Database Syst Rev 2011; DOI: 10.1002/14651858.CD003175.pub2

46 Goldfinger M, Diaz I, Muggia F. Systemic treatment of endometrial cancer: what is doxorubicin's role? J Clin Oncol 2014; 32: 2181-2182

47 Carlson MJ, Thiel KW, Leslie KK. Past, present, and future of hormonal therapy in recurrent endometrial cancer. Int J Womens Health 2014; 6: $429-435$

48 Gurumurthy $M$, Somoye $G$, Cairns $M$ et al. An update on the management of uterine carcinosarcoma. Obstet Gynecol Surv 2011; 66: 710716

49 Galaal K, van der Heijden E, Godfrey K et al. Adjuvant radiotherapy and/ or chemotherapy after surgery for uterine carcinosarcoma. Cochrane Database Syst Rev 2013; 2: CD006812 